\title{
Power Management of Shopping Mall with Smart Car Park Storage
}

\author{
Xiaoke Su and Hong Yue \\ Wind Energy and Control Centre, Department of Electronic and Electrical Engineering \\ University of Strathclyde \\ Glasgow G1 1XW, UK \\ xiaoke.su@strath.ac.uk; hong.yue@strath.ac.uk
}

\begin{abstract}
A smart car park with electrical vehicles (EVs) has the potential to participate in a commercial building's energy storage and power supply activities, via bidirectional power flow techniques. In this paper, the management of energy usage of a shopping mall with smart car park is investigated. An optimal control model is built up to determine EVs' charging/discharging status under real-time price, the on/off switching of the heating, ventilation and air conditioning (HVAC) unit in the shopping mall, so that the overall energy cost can be minimised under normal and emergency operations. Key factors such as EV battery degradation, constraints on battery states and the emergency power supply requirements are included in the model. Simulation studies demonstrate that a proper-sized smart car park can be used as an extra power supply to the shopping mall under emergency power shut down. This can help to reduce reliance on traditional power supply under emergency requirements.

Index Terms-electric vehicle (EV), smart car park, shopping mall, emergency power supply, constrained optimisation
\end{abstract}

\section{INTRODUCTION}

The use of electrical vehicles (EVs) provides a solution to reduce carbon emission to environment and is essential for decarbonising mobility [1]. With a smart car park system, the charging and discharging strategy for EV batteries can be managed in an economical way to make profits for EV users [2]. Meanwhile, a smart car park can be used as a battery storage system for other demands and grid stability [3].

There are recent studies on bidirectional power flow in shopping mall systems with EV car park charging equipment. Modern shopping malls typically have large car parks, for example, a shopping mall in Istanbul, Turkey, hosts on average 350-400 EVs per day [4]. The large capacity of EV batteries in a car park can be taken as energy storage to balance power usage and achieve economic benefits [5]. Shopping mall owners have the option to reduce their peak electricity usage under a dynamic pricing schedule as compared to the control group under traditional flat tariffs [6]. To maximise a mall charging station's profits, an efficient means of charging EVs arriving at a shopping mall is presented without considering vehicle-to-grid (V2G) activities [7].

Emergency power supply to shopping centres usually depend on traditional techniques such as natural gas electric generating devices or diesel electric generating devices. Use of clean energy for power backup still needs to be better understood on its reliability, scalability and costs, etc. One evaluation of renewable energy (photovoltaic) and conventional electricity generation (diesel generator) is made in [8], where the shopping mall building needs extra power supply to meet the power requirement under emergency power cut-off. In this context, a smart car park system with bidirectional power flow functions can be a part of extra backup to shopping mall's emergency power supply. The above works have suggested technical feasibility of EV car park as energy storage for shopping mall power supply under normal and emergency operations.

Since the battery degradation cost is much higher than the V2G profits, EVs in a shopping mall's car park do not operate in discharging status in normal situation under optimal control. However, in occurrence of emergent power shut-down, the shopping mall must maintain its basic operations within a short period, it is necessary to get power supply from the backup system. If a rewarding price is provided, the EV car park could be used as part of the backup system. This drives our research towards a systematic design in an optimisation framework.

In this work, we aim to investigate how to manage power usage for a shopping mall with a smart car park. For the car park with multiple EVs, the EV charging/discharging strategy can be developed to minimise electricity cost under the realtime price. In most shopping centres, the air temperature is maintained by the heating, ventilation and air conditioning (HVAC) system, which consumes a large amount of energy [9]. The most simple control of HVAC is through an onoff switching operation. Under emergency situations when the power from grid supply becomes unavailable, diesel energy generation and car park EV energy storage will be used to supply power for basic building operation. The charging/discharging of EVs and the on/off switching of HVAC are determined through the energy cost optimisation design. Relevant constraints on battery state of charge (SOC) and building temperature requirement are considered in the optimisation model.

The rest of the paper is organised as follows. The system configuration and the electricity cost model is presented in Section II, which involves EV car park electricity cost, HVAC operation cost and the cost for other loads. In Section III, management of power supply from the car park to the shopping mall under emergency power shut down is designed. Section IV provides a case study by using the proposed method and 
collected real data. Conclusions are given in Section V.

TABLE

NOMENCLATURE AND ACRONYMS

\begin{tabular}{ll}
\hline Nomenclature & \\
\hline$N$ & number of vehicles in car park \\
$M$ & number of samplings in time \\
$u_{i}(t)$ & charging/discharging status variable at time $t$ \\
$Z_{H V A C}(t)$ & HVAC on/off status variable at time $t$ \\
$P_{1}$ & power for charging EVs in car park $(\mathrm{kWh})$ \\
$P_{2}$ & power demand for HVAC $(\mathrm{kWh})$ \\
$P_{3}$ & other loads $(\mathrm{kWh})$ \\
$P_{4}$ & car park power supply under emergency $(\mathrm{kWh})$ \\
$P_{5}$ & diesel generator power supply under emergency $(\mathrm{kWh})$ \\
$P_{\text {grid }}$ & grid power supply $\mathrm{kWh})$ \\
$P_{E V}$ & charging and discharging power of an EV $(\mathrm{kW})$ \\
$C_{1}$ & energy cost of car park EV charging $(\$)$ \\
$C_{2}$ & energy cost of HVAC $(\$)$ \\
$C_{3}$ & energy cost of other loads $(\$)$ \\
$C_{4}$ & cost of power backup from car park $(\$)$ \\
$C_{5}$ & cost of power backup from diesel generator $(\$)$ \\
$C_{g r i d}$ & cost paid for grid power $(\$)$ \\
$C_{\text {total }}$ & total electricity cost $(\$)$ \\
$C_{\text {charge }}$ & cost of EV charging $(\$)$ \\
$C_{\text {discharge }}$ & cost of EV discharging $(\$)$ \\
$C_{1, l o s s}$ & charging battery degradation cost $(\$)$ \\
$C_{4}$, loss & discharging battery degradation cost $(\$)$ \\
$\Delta t$ & sampling time period for power management $(\mathrm{h})$ \\
$S O C_{\text {min }}$ & minimum state of charge \\
$S O C_{\text {max }}$ & maximum state of charge \\
$S O C_{\text {final }}$ & final SOC requirement \\
$S O C(t)$ & SOC at time $t$ \\
$T_{\text {in }}(t)$ & indoor temperature at time $t\left({ }^{\circ} \mathrm{C}\right)$ \\
$T_{\text {out }}(t)$ & outdoor temperature at time $t\left({ }^{\circ} \mathrm{C}\right)$ \\
$\Delta T(t)$ & outdoor and indoor temperature difference $\left({ }^{\circ} \mathrm{C}\right)$ \\
$\lambda, \lambda^{*}$ & threshold values in temperature constraints $\left({ }^{\circ} \mathrm{C}\right)$ \\
$\beta_{\text {on }}$ and $\beta_{\text {off }}$ & HVAC parameters \\
$D_{r}$ & Battery degradation rate $(\$ / k W h)$ \\
$p(t)$ & Grid power price at time $t(\$ / k W h)$ \\
$q(t)$ & Feed-in tariff at time $t(\$ / k W h)$ \\
$\gamma$ & unit price for diesel generation $(\$ / k W h)$ \\
\hline Acronyms & \\
\hline $\mathrm{EV}$ & electric vehicle \\
$\mathrm{FIT}$ & feed-in tariff \\
$\mathrm{SOC}$ & state of charge \\
$\mathrm{V} 2 \mathrm{G}$ & vehicle to grid \\
$\mathrm{G} 2 \mathrm{~V}$ & grid to vehicle \\
$\mathrm{HVAC}$ & heating, ventilation, and air conditioning \\
\hline &
\end{tabular}

\section{SYSTEM CONFIGURATION AND ENERGY COST MODEL}

\section{A. System Configuration}

The shopping mall power system can be balanced by two parts, the power supply and the power consumption (loads). Fig.1 shows the system configuration, in which the car park, the building HVAC and other loads are on the load side. On the supply side, grid power is used for normal situation; in case of emergency power off, the car park energy storage and a diesel generator are used for power supply to the shopping mall. Here $P_{1}$ is EVs charging power in car park, $P_{2}$ is the power consumed by HVAC operation, $P_{3}$ represents other loads, $P_{4}$ is the discharging power from car park storage, $P_{5}$ is the diesel generation power, and $P_{\text {grid }}$ is the grid power. $P_{4}$ and $P_{5}$ are zeros under normal grid supply. In Fig.1, an arrow pointing towards a block indicates that the power flows into the block,

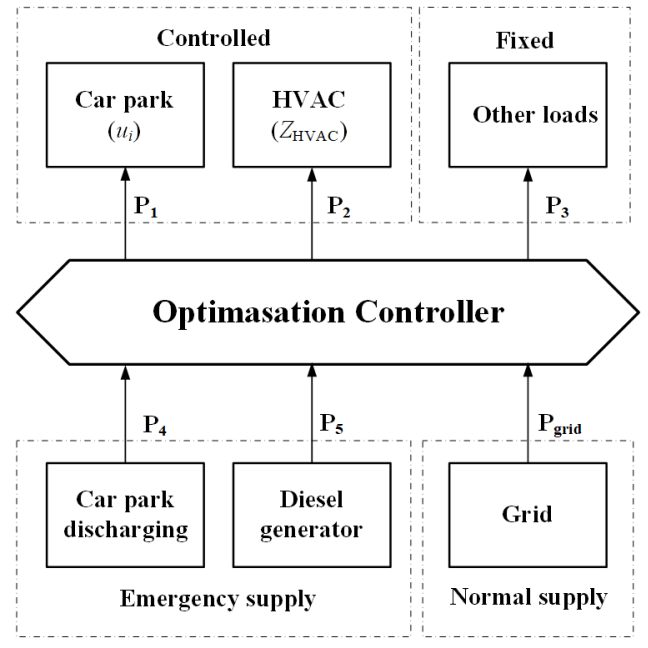

Fig. 1. Configuration of shopping mall power system with car park

an arrow leaving from a block means that block functions for power supply. The power balance function is therefore

$$
P_{1}+P_{2}+P_{3}=P_{\text {grid }}+P_{4}+P_{5}
$$

In this system, it is assumed that the electricity power usage can be managed by controlling EVs' charging/discharging status and on/off switching of HVAC. The other loads term is fixed.

An EV can have three statuses, charging, discharging and disconnect. Denote $u_{i}$ as the charging/discharging control variable for the $i$-th $\mathrm{EV}(i=1, \ldots, N)$, at time $t$, it can be written by the following function.

$$
u_{i}(t)=\left\{\begin{array}{cl}
-1, & \text { charging } \\
1, & \text { discharging } \\
0, & \text { disconnect }
\end{array}\right.
$$

The HVAC system is assumed to be simply controlled at two statuses, on and off, denoted by a binary control variable

$$
Z_{H V A C}(t)= \begin{cases}1, & \text { on } \\ 0, & \text { off }\end{cases}
$$

The values of signal $u_{i}(t)$ and $Z_{H V A C}(t)$ are determined by the optimisation controller, with the aim to minimise the overall energy cost while meeting the operation requirements of the system in Fig.1.

\section{B. EV Car Park Cost Model}

The cost of electricity power in car park $\left(C_{1}\right)$ covers the EV charging cost $\left(C_{\text {charge }}\right)$ and the cost for battery degradation due to charging $\left(C_{1, \text { loss }}\right)$, i.e.

$$
C_{1}=C_{\text {charge }}+C_{1, \text { loss }}
$$

Define

$$
\operatorname{sgn}^{+}(x)= \begin{cases}x, & \text { if } x>0 \\ 0, & \text { if } x \leq 0\end{cases}
$$


Within a monitoring period with sampling times from $t=1$ to $t=M$, the charging cost of the $i$-th EV can be calculated by

$$
C_{\text {charge }}^{i}=\sum_{t=1}^{M} p(t) \cdot \operatorname{sgn}^{+}\left(u_{i}(t)\right) \cdot P_{E V} \cdot \Delta t
$$

where $p(t)$ is the price of electricity, $P_{E V}$ is the charging power, $\Delta t$ is the sampling period. In this work, it is assumed that the same value of $P_{E V}$ is used for all vehicles in the car park under both charging and discharging status.

Battery degradation occurs during both charging and discharging operation. Using a fixed degradation rate, $D_{r}$, for both charging and discharging, the battery degradation cost for the $i$-th $\mathrm{EV}$ can be calculated by

$$
C_{1, \text { loss }}^{i}=\sum_{t=1}^{M} D_{r} \cdot\left(\operatorname{sgn}^{+}\left(u_{i}(t)\right)\right) \cdot P_{E V} \cdot \Delta t
$$

The total cost for charging all EVs in the car park can be calculated from (4), (6) and (7) to give

$$
C_{1}=\sum_{i}^{N}\left(C_{\text {charge }}^{i}+C_{1, \text { loss }}^{i}\right) \text {. }
$$

Constraints on batteries need to be considered for EV operations. For an EV battery, its SOC needs to stay between the required lower and upper bounds at any time, i.e.,

$$
S O C_{\min } \leq S O C_{i}(t) \leq S O C_{\max }
$$

where $S O C_{i}(t)$ is the $\mathrm{SOC}$ for the $i$-th $\mathrm{EV} ; S O C_{\min }$ and $S O C_{\max }$ are the lower and upper bounds for SOC. In this work, the boundary constraints are considered to be the same for all EVs in the car park. In addition, each EV must be charged to a required SOC level, denoted as $S O C_{\text {final }}$, to allow its drive after leaving the car park, that is,

$$
S O C_{\text {final }} \geq a
$$

where $a(0<a<1)$ is a given threshold. Calculation of SOC can be found in our previous work [2] and other literature.

\section{EV Battery Capacity Adjustment}

EV batteries are different in rated capacity for different EV models. In this work, we take six rated capacities between $60 \mathrm{kWh}$ to $120 \mathrm{kWh}$ in the following distribution: $60 \mathrm{kWh}(2.5 \%), 70 \mathrm{kWh}(13.5 \%), 80 \mathrm{kWh}(34 \%), 90 \mathrm{kWh}$ (34\%), 100kWh (13.5\%) and over 110kWh (2.5\%).

For used EVs, the full capacity is lower than the rated level due to performance degradation. This degradation is counted by an degradation factor, which is assumed to be within 0.9 to 0.7 following an exponential function. That means the full capacity of each EV is assumed to be $70 \%$ to $90 \%$ of its rated capacity.

The distribution of EVs in terms of the rated capacity and the degradation factor is shown in Fig.2. For each EV in the car park, its capacity is adjusted by the rated capacity multiplied by the degradation factor.

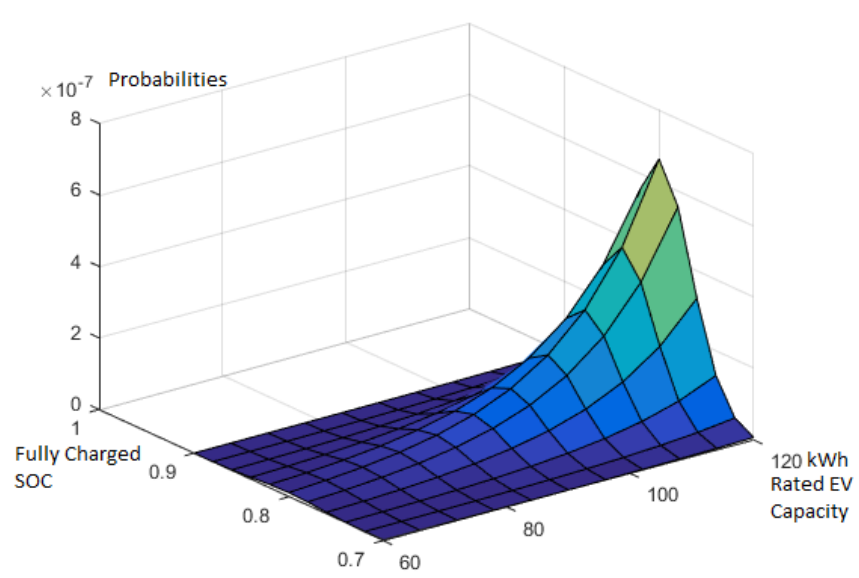

Fig. 2. Distribution of EV batteries w.r.t. rated capacity and degradation factor

\section{HVAC System}

The HVAC system is used to maintain the indoor temperature of the shopping mall. It is assumed to operate at two status, on and off. The following HVAC model adapted from [10] is employed in this study. At time $\tau$, the power demand for indoor cooling and heating is written following the first law of thermodynamics

$$
\begin{aligned}
\tilde{P}_{2}(\tau)= & \left(\left(\beta_{\text {on }}-\beta_{\text {off }}\right) \cdot Z_{H V A C}(\tau)+\beta_{\text {off }}\right) \\
& \cdot\left(T_{\text {out }}(\tau)-T_{\text {in }}(\tau)\right)
\end{aligned}
$$

$T_{\text {in }}(\tau)$ and $T_{\text {out }}(\tau)$ are the indoor and outdoor temperatures at time $\tau ; Z_{H V A C}$ is the binary variable controlling HVAC operation; $\beta_{o n}$ and $\beta_{\text {off }}$ are two parameters related to the outdoor temperature. Since the calculation step for HVAC dynamics is smaller than the sampling period $(\Delta t)$ for power management calculation, the sequence of $P_{2}(t)$ is sampled from the sequence of $\tilde{P}_{2}(\tau)$ using a sampling period of $\Delta t$.

The cost of HVAC power load over the monitoring period can be calculated by

$$
C_{2}=\sum_{t=1}^{M} P_{2}(t) \cdot p(t) \cdot \Delta t
$$

The difference between the indoor and outdoor temperatures should be controlled below a given level. A constant $\lambda$ is introduced to represent this constraint as in [11]:

$$
\Delta T(t)=\mid\left(T_{\text {out }}(t)-T_{\text {in }}(t) \mid \leq \lambda .\right.
$$

\section{E. Other Loads}

The end-use demand plays an important role in effective power management in a smart grid building system [11]. In this work, the priorities are given to the car park load and the HVAC load, all other loads including end-use demand are grouped together as a fixed term in $P_{3}$. Data from demand 
side are collected to estimate $P_{3}$. The cost of other loads can therefore be calculated by a simple model

$$
C_{3}=\sum_{t=1}^{M} P_{3} \cdot p(t) \cdot \Delta t
$$

\section{F. Optimisation Design}

Under normal grid supply, the total power cost of the system consists of $C_{1}, C_{2}$ and $C_{3}$ that can be calculated by (8), (12) and (14), among them $C_{3}$ is a fixed term from other loads, only the EV car park cost $\left(C_{1}\right)$ and the HVAC cost $\left(C_{2}\right)$ can be managed through control. To minimise $C_{1}$ for the EV car park system, the EV charging strategy can be determined from the following optimisation design.

$$
\begin{aligned}
\mathbf{u}^{*}= & \arg \min C_{1} \\
\text { s.t. } & S O C_{\text {min }} \leq S O C_{i}(t) \leq S O C_{\text {max }} \\
& S O C_{\text {final }} \geq a
\end{aligned}
$$

Here $\mathbf{u}^{*}$ is the charging status vector collating $u_{i}(t)$ for all EVs $(i=1, \cdots, N)$ at all sampling time points $(t=1, \cdots, M)$.

For the HVAC cost minimisation, similarly, the on/off switching status can be determined from the following optimisation design.

$$
\begin{aligned}
& \mathbf{Z}^{*}=\arg \min C_{2} \\
& \text { s.t. } \Delta T(t) \leq \lambda
\end{aligned}
$$

where $\mathbf{Z}^{*}$ is the control vector including switching status variable $Z_{H V A C}(t)$ at all sampling times $(t=1, \cdots, M)$.

The two optimisation problems in (15) and (16) are nonconvex integer optimisation problems. In this work, a heuristic global optimisation method, Genetic Algorithm (GA), is chosen to obtain the solution.

\section{BACKup Supply IN EMERGENCY POWER OFF}

\section{A. Cost for Car Park for Emergency Support}

When power supply from the grid is cut off due to technical faults or weather conditions, the shopping mall power system will be run under emergency mode. Backup sources such as diesel generation will be used to supply power to maintain basic operations until the system is back to normal power supply. In this work, we consider to use car park power storage as another backup source to supply power under emergency situation. Denote $P_{5}$ as diesel generator power and $P_{4}$ as the power provided from the car park, a new power balance is obtained for the system in Fig.1 as

$$
P_{1}+P_{2}+P_{3}=P_{4}+P_{5}
$$

The cost of emergency power supply includes the cost of diesel generation power $\left(C_{5}\right)$ and the power cost for car park $\mathrm{EV}$ discharging $\left(C_{4}\right)$. The cost for the discharged power is calculated by

$$
C_{\text {discharge }}=\sum_{i=1}^{N} \sum_{t=1}^{M} q \cdot \operatorname{sgn}^{+}\left(-u_{i}(t)\right) \cdot P_{E V} \cdot \Delta t
$$

where $q$ is the price paid for emergency power supply by EV discharging. This is considered to be a constant during the short period of emergency. The battery degradation cost due to discharging is calculated by

$$
C_{4, \text { loss }}=\sum_{i=1}^{N} \sum_{t=1}^{M} D_{r} \cdot \operatorname{sgn}^{+}\left(-u_{i}(t)\right) \cdot P_{E V} \cdot \Delta t
$$

The total cost for car park due to discharging is therefore

$$
C_{4}=C_{\text {discharge }}+C_{4, \text { loss }}
$$

\section{B. Diesel Power Generation}

In this study, the power from diesel generator $\left(P_{5}\right)$ is calculated from (17). It contributes to part of the emergency power supply. The cost for this part is calculated by

$$
C_{5}=P_{5} * \gamma
$$

where $\gamma$ is the unit price for $P_{5}$ which is a constant.

\section{Design for Emergency Power Supply}

In this work, the whole car park is taken as an energy storage system that hold power from all EV batteries. With the proposed emergency power supply scheme, some EVs in the car park are used to supply power to shopping mall from discharging activities, some still need to charge power if the EV's SOC is below the required $S O C_{\text {final }}$. The price paid for discharging power shouldn't be less than the cost of charging power and the degradation costs from both charging and discharging activities, i.e.,

$$
C_{\text {discharge }} \geq C_{\text {charge }}+C_{1, \text { loss }}+C_{4, \text { loss }}
$$

otherwise the car park will lose money from participating the scheme.

When the shopping mall is under the emergency operation mode, the power supply will be prioritised for basic demands. The constraint on EV battery SOC is relaxed to save more storage power for the demand side. The adjusted constraint is

$$
S O C_{\text {final }} \geq b
$$

Here $b$ is the decreased threshold $(b<a)$ for $S O C_{\text {final }}$ under emergency operation mode.

Similarly, the threshold for indoor and outdoor temperature difference $\Delta T$ is changed to $\lambda^{*}\left(\lambda^{*} \leq \lambda\right)$, that is,

$$
\Delta T(t) \leq \lambda^{*}
$$

For emergency power supply, there's no need to optimise EV charging and discharging as in (15). The HVAC control can be the same as in (16) if manageable. 


\section{CAse Study}

\section{A. System Setting}

A typical shopping mall with $40(N=40)$ EV charging slots is considered for the case study. The use of electricity is assessed from $9 \mathrm{am}$ to $5 \mathrm{pm}$, divided into $16(M)$ time slots with 0.5 hour $(\Delta t)$ each. The maximum SOC is 0.9 and the minimum SOC is 0.2. It is required that the SOC is not less than $0.7(a=0.7)$ at the end of the day in normal situation and $0.5(b=0.5)$ for emergency power supply.

In this work the commercial charging facility is assumed which can fully charge an EV in less than 3 hours, the voltage is 220 volts and the charging/discharging power $P_{E V}$ is 13.2 $k W$.

The battery degradation cost $D_{r}$ is taken to be $0.3 \$ / k W h$ [12]. The unit price for diesel power generation $\gamma$ is 0.34 $\$ / k W h$. The price of purchasing power from grid $p$ is a realtime-pricing (RTP) setting, given as $[0.26,0.28,0.30,0.32$, $0.28,0.22,0.20,0.22] \$ / k W h$ from $9 \mathrm{am}$ to $5 \mathrm{pm}$ in the normal situation.

The building's inside temperature is set to $23^{\circ} \mathrm{C}$. The outdoor temperature is set to $20^{\circ} \mathrm{C}$ in the morning from 9am to $12 \mathrm{pm}$ and $25^{\circ} \mathrm{C}$ in the afternoon from $12 \mathrm{pm}$ to $5 \mathrm{pm}$. The HVAC parameter $\beta_{o n}$ is set to 1 and $\beta_{\text {off }}$ is set to 0.4 as in [10]. $\lambda$ is set to $7^{\circ} C$ for normal operation and $\lambda^{*}$ is $2^{\circ} C$ for emergency operation. The term of other loads $P_{3}$ is set to be $200 \mathrm{kWh}$.

The diesel generation power $P_{5}$ is set to $200 \mathrm{kWh}$ as backup power for emergency supply.

\section{B. Normal and Emergency Power Supply}

For both the normal and emergency simulations, the initial settings of the $40 \mathrm{EVs}$ are randomly selected from the grid points generated in Fig.2. To simulate the emergency scenario, the power-off time period is set from 10am to 11am.

The calculated results for cost splits and power elements are shown in Table II. The total power costs of the system are $\$ 212.6$ under normal power supply and \$367.9 for emergency situation. The data listed for emergency scenario covers power usage over the whole 8 hours' assessing period including the 7 hours under normal operation and the 1 hour under emergency backup supply.

\section{EV Variation Analysis for Emergency Power Supply}

To further examine the proposed strategy for emergency power supply, a large number of initial settings are selected to simulate variations of EVs and their initial SOC in a car park. Sample size of 1000, 2000, 5000 and 10000 initial conditions are implemented, in which EV capacities are taken randomly from points in Fig.2. From these simulation, the worst case (lower bound) can be identified under which the emergency power supply requirement is still satisfied.

The results of lower bounds for $C_{1}$ and $C_{\text {total }}$ are shown in Table III. This simulation validates that the size of a smart car park with $40 \mathrm{EVs}$ is capable of providing emergency power supply to the case study shopping mall system under various initial EV conditions.

\section{Simulation on Different Emergency Time Slots}

In this section, simulations are made on different power-off time periods, each one lasts for 1 hour. The results are given in Table IV.

The results show that, for the case study shopping mall with $40 \mathrm{EV}$ charging slots, the smart car park capacity can be used for part of backup power supply for one-hour emergency power off.

\section{E. Simulation on Different Temperature Difference and EV Numbers}

In this section, we first discuss the impact of EV number to the cost results. By fixing other factors in Section IV-A, the number of EVs is changed from 20 to 70 , the costs are calculated and listed in the Table V. The simulation results show that the number of EVs must be over 35 in order to satisfy the requirement of emergency power supply for the case study shopping mall. When the number of vehicles is too small, the proposed strategy fails to return a solution under some initial conditions of EVs.

In the next simulation, the impact of indoor and outdoor temperature difference $(\Delta T)$ is discussed. Under normal operations, a threshold of $\lambda=7$ is applied for building temperature control. Under emergency situations, this threshold level can be lowered to reduce power consumption for temperature control and allow more car park storage for emergency demands. The threshold for temperature control under emergency power supply is denoted by $\lambda^{*}$ as in (24).

By changing $\lambda^{*}$ from 1 to 7 , the results for required number of EVs and the costs are listed in Table VI. It can be seen that when the temperature control demand is reduced, i.e. smaller $\lambda^{*}$, the minimum number of EVs required to support the scheme is also reduced and so does the total cost.

\section{CONClusion}

This paper proposed a power management scheme for a shopping mall system with EV car park. Two different operation scenarios are considered. For the normal operation with power supply from the grid, an optimal control model is proposed to minimise the total cost by controlling EVs' charging status and HVAC's on/off status. For emergency power off situation, the car park storage and the diesel generation are used as backup power supply. Simulations are made on a case study system. The results demonstrate the feasibility of using a large-scale smart car park as backup energy storage for emergency use when the grid power is cut off. This provides a solution to reduce traditional power supply under emergency situation, and promotes the use of more cleaning energy.

In this work, the power control of car park and HVAC are handled by two constrained optimisation problems. Considering more complicated power use demands, e.g., the priority of power supply between multiple subsystems, the combined control of EVs and HVAC may be required, which makes a challenging optimisation problem. Other factors, such as variations in customer flow, environmental temperature, can be 
TABLE II

RESULTS OF POWER SPLIT AND COSTS UNDER NORMAL AND EMERGENCY POWER SUPPLY

\begin{tabular}{|c|c|c|c|c|c|c|c|c|c|c|c|}
\hline & $C_{\text {total }}(\$)$ & $C_{1}(\$)$ & $C_{2}(\$)$ & $C_{3}(\$)$ & $C_{4}(\$)$ & $C_{5}(\$)$ & $P_{1}(k W h)$ & $P_{2}(\mathrm{kWh})$ & $P_{3}(\mathrm{kWh})$ & $P_{4}(\mathrm{kWh})$ & $P_{5}(\mathrm{kWh})$ \\
\hline Normal & 212.6 & 135.2 & 25.4 & 52.0 & 0 & 0 & 520.0 & 97.5 & 200 & 0 & 0 \\
\hline Emergency & 367.9 & 147.5 & 26.8 & 67.0 & 58.6 & 68.0 & 557.3 & 80.2 & 200 & 68.1 & 200 \\
\hline
\end{tabular}

TABLE III

COST LOWER BOUNDS FOR DIFFERENT INITIAL SETTINGS

\begin{tabular}{lrc}
\hline Sampling & Lower $C_{1}(\$)$ & Lower $C_{\text {total }}(\$)$ \\
\hline 1,000 & 213.4 & 359.9 \\
2,000 & 210.3 & 357.6 \\
5,000 & 209.4 & 357.4 \\
10,000 & 208.9 & 357.0 \\
\hline
\end{tabular}

TABLE IV

COST LOWER BOUNDS FOR DifFERENT EMERGENCY TIME SLOTS

\begin{tabular}{lcc}
\hline Cut down time & Lower $C_{1}(\$)$ & Lower $C_{\text {total }}(\$)$ \\
10:00-11:00 & 177.3 & 332.7 \\
11:00-12:00 & 212.0 & 359.9 \\
12:00-13:00 & 240.0 & 374.3 \\
13:00-14:00 & 221.4 & 362.4 \\
14:00-15:00 & 210.3 & 357.8 \\
15:00-16:00 & 211.4 & 358.2 \\
16:00-17:00 & 209.5 & 359.1 \\
\hline
\end{tabular}

TABLE V

NUMBER OF EVS AND COSTS

\begin{tabular}{cccc}
\hline $\mathrm{N}$ & Lower $C_{1}(\$)$ & $C_{\text {total }}(\$)$ & Upper $C_{1}(\$)$ \\
\hline 20 & N/A & N/A & N/A \\
25 & N/A & N/A & 253.4 \\
30 & N/A & N/A & 255.8 \\
35 & 240.0 & 376.4 & 271.2 \\
40 & 213.4 & 362.4 & 250.4 \\
50 & 210.7 & 359.6 & 248.3 \\
60 & 216.4 & 355.1 & 239.3 \\
70 & 216.4 & 356.5 & 226.4 \\
\hline
\end{tabular}

TABLE VI

NUMBER OF EVS AND TOTAL COST FOR DIFFERENT $\lambda^{*}$

\begin{tabular}{ccc}
\hline$\lambda^{*}\left({ }^{\circ} \mathrm{C}\right)$ & Minimal EVs required & $C_{\text {total }}(\$)$ \\
\hline 1 & 26 & 320.4 \\
2 & 31 & 348.4 \\
3 & 35 & 356.6 \\
4 & 39 & 365.4 \\
5 & 44 & 371.5 \\
6 & 47 & 383.6 \\
7 & 51 & 399.9 \\
\hline
\end{tabular}

added to the proposed framework but need more investigation to understand their impacts.

\section{REFERENCES}

[1] J. Henderson, "EVs are not the answer: a mobility justice critique of electric vehicle transitions," Annals of the American Association of Geographers, vol. 110, no. 6, pp. 1993-2010, 2020.

[2] X. Su, H. Yue, and X. Chen, "Cost minimization control for electric vehicle car parks with vehicle to grid technology," Systems Science \& Control Engineering, vol. 8, no. 1, pp. 422-433, 2020.
[3] L. Cai, P. Hu, and Z. Tan, "Research on the effect of large-scale electric vehicle based on smart wearable equipment access to grid," Journal of Ambient Intelligence and Humanized Computing, vol. 10, no. 8, pp. 3231-3237, 2019.

[4] G. Poyrazoglu and E. Coban, "A stochastic value estimation tool for electric vehicle charging points," Energy, vol. 227, p. 120335, 2021.

[5] B. Lin and W. Wu, "Economic viability of battery energy storage and grid strategy: A special case of china electricity market," Energy, vol. 124, pp. 423-434, 2017.

[6] A. Faruqui, S. Sergici, and C. Warner, "Arcturus 2.0: A meta-analysis of time-varying rates for electricity," The Electricity Journal, vol. 30, no. 10, pp. 64-72, 2017.

[7] M. Athulya, A. Visakh, and M. Selvan, "Electric vehicle recharge scheduling in a shopping mall charging station," in 2020 21st National Power Systems Conference (NPSC). IEEE, 2020, pp. 1-6.

[8] F. B. Budes, G. V. Ochoa, and Y. C. Escorcia, "An economic evaluation of renewable and conventional electricity generation systems in a shopping center using homer pro®," Contemporary Engineering Sciences, vol. 10, no. 26, pp. 1287-1295, 2017.

[9] A. Mondal and S. Bhattacharya, "Energy efficient and effective control strategy of HVAC system in large shopping complex," in 2014 3rd International Conference on Eco-friendly Computing and Communication Systems. IEEE, 2014, pp. 116-120.

[10] H.-C. Jo, S. Kim, and S.-K. Joo, "Smart heating and air conditioning scheduling method incorporating customer convenience for home energy management system," IEEE transactions on consumer electronics, vol. 59, no. 2, pp. 316-322, 2013.

[11] S. Puradbhat and R. Banerjee, "Estimating demand side management impacts on buildings in smart grid," in 2014 IEEE Innovative Smart Grid Technologies-Asia (ISGT ASIA). IEEE, 2014, pp. 635-640.

[12] S. B. Peterson, J. Whitacre, and J. Apt, "The economics of using plug-in hybrid electric vehicle battery packs for grid storage," Journal of Power Sources, vol. 195, no. 8, pp. 2377-2384, 2010. 